\title{
Microstructure and physical properties of nano charcoal ash as binder
}

Siti Nur Amiera Jeffry MEng

PhD student, Department of Geotechnics and Transportation, Faculty of Civil Engineering, Universiti Teknologi Malaysia, UTM Johor Bahru, Johor, Malaysia

\section{Ramadhansyah Putra Jaya PhD}

Senior Lecturer, Department of Geotechnics and Transportation, Faculty of Civil Engineering, Universiti Teknologi Malaysia, UTM Johor Bahru, Johor, Malaysia (corresponding author: ramadhansyah@utm.my)

\section{Norhidayah Abdul Hassan PhD}

Senior Lecturer, Department of Geotechnics and Transportation, Faculty of Civil Engineering, Universiti Teknologi Malaysia, UTM Johor Bahru, Johor, Malaysia

\author{
Jahangir Mirza PhD \\ Professor, Department of Materials Science, Research Institute of \\ Hydro-Québec, Varennes, Québec, Canada \\ Mohd Ibrahim Mohd Yusak MEng \\ PhD student, Department of Geotechnics and Transportation, Faculty \\ of Civil Engineering, Universiti Teknologi Malaysia, UTM Johor Bahru, \\ Johor, Malaysia
}

Waste coconut shell (CS) was used to produce nano charcoal ash (NCA) as a potential modifier material in an asphalt binder. This study focused on the microstructural and physical properties of NCA. Thermogravimetric analysis and derivative thermogravimetric analysis (TGA/DTA), field emission scanning electron microscopy (FESEM), X-ray fluorescence, particle size analysis (PSA), penetration tests, softening point tests and dynamic shear rheometer (DSR) tests were performed. The TGA/DTA results revealed $490^{\circ} \mathrm{C}$ to be a suitable CS burning temperature to form carbon and to reduce impurities. The morphology determined by FESEM showed that charcoal CS presents a smooth, porous and irregular shape. The carbon content on the surface of the material was $77.6 \%$, as indicated by energy-dispersive X-ray spectroscopy. PSA showed that the optimum size of the charcoal CS obtained after several grinding cycles was $148 \mathrm{~nm}$. Test results indicated that adding NCA from coconut shell to bitumen improved the binder stiffness up to $47 \%$ and significantly increased the softening point up to $12 \%$ compared with virgin binder. The DSR test revealed that the optimum size of NCA enhanced the bitumen by increasing the resistance to rutting until a temperature of $76^{\circ} \mathrm{C}$ was reached, prior to failure at a temperature of $82^{\circ} \mathrm{C}$.

\section{Introduction}

In Malaysia, $95 \%$ of the pavement is constructed from asphaltic concrete (Che Mat et al., 2014). Proper bonding between the bitumen and the aggregate is very important to ensure that construction using asphaltic concrete is strong and durable, provides a smooth surface and can accommodate traffic loadings adequately. However, due to increasing traffic volume, greater loads and pressures are applied on asphalt pavements by various vehicles, including heavy lorries and trucks. In addition, its susceptibility to high temperature leads to changes in the properties of bitumen, which cause pavement distress such as rutting and fatigue cracking, and reduces the performance of asphalt pavements (Hainin et al., 2013, 2014, 2015).

These are the reasons why modifiers and additives are being introduced into the asphalt binder. The main advantages of the modified binder in terms of engineering factors are that the properties of the bitumen will be improved and there will be a high resistance to rutting and fatigue cracking and a decrease in temperature susceptibility. In terms of environmental and economic factors, the waste materials and the maintenance costs, respectively, can be reduced. Numerous modifiers have been used in previously published studies; these include polymers, industrial by-products, waste materials and agricultural waste materials. In addition, the potential of agricultural waste materials such as palm oil fuel ash, palm kernels, rice husk ash and coconut shell (CS) as bitumen modifiers has been more extensively explored in the current concrete and asphalt pavement industries. This is a result of the high increment in the disposal of natural resources. Thus, rather than throwing them away, it is better to reuse them in other applications, such as modifiers in asphalt binders. Through this alternative, not only can wastes be reduced but they can also be used to enhance the properties of asphalt binders. From all the research on using agricultural waste materials, it seems that CS has so far been very little used as a modifier in asphalt binders. Based on previous research, CS has potential as a filler in composite structures (Agunsoye et al., 2012, 2014; Husseinsyah and Zakaria, 2011; Kumar and Kumar, 2012; Madakson et al., 2012; Sapuan et al., 2003; Sarki et al., 2011; Singh, 2013) and as an aggregate in concrete and asphalt mixtures (Gunasekaran, 2011; Gunasekaran et al., 2011, 2012, 2013; Jeffry et al., 2016; Norhafizah et al., 2016; Ramadhansyah et al., 2016) Coconut is one of the crops 
that grows in tropical countries such as Malaysia, Indonesia, Philippines, Thailand and India. According to FAOStat (2015), Malaysia is the tenth largest coconut grower in the world with a production of $624727 \mathrm{t}$ of coconuts. In addition, coconut is the fourth largest crop in Malaysia after palm oil, rubber and paddy (FAOStat, 2015). The Malaysian Agricultural Research and Development Institute has conducted extensive research and development studies involving coconut (Sivapragasam, 2008). CS is widely discharged by various industries, thereby leading to environmental pollution.

There are numerous coconut-based products being produced such as coconut oil, desiccated coconut, coconut milk powder, CS charcoal and activated carbon (Sivapragasam, 2008). Of all the products, charcoal CS is widely produced to be used in many types of applications and has many benefits. Commonly, charcoal is known as a black material containing carbon as the main chemical component. It is usually produced by burning or heating wood without air in an enclosed space. Charcoal is usually used as a fuel and it is recognised as a 'green' material because it is safe to use. The Food and Drug Administration has stated that plain charcoal, which is safe and effective, is categorised as category 1 (Nath Giri, 2015). Charcoal CS has been used in various research fields because it is efficient, environmentally friendly and economical, and it has the potential to enhance the properties of composite materials (Ouyang et al., 2013; Pukird et al., 2009; Rampe et al., 2011; Read and Whiteoak, 2003).

Recently, nanotechnology has drawn the interest of researchers from various fields. Generally, nano is a scale of size in the metric system which is one-billionth of a metre. Figure 1 shows the scale of various items from the milliscale to the nanoscale. It can be seen how small the nanoscale is compared with other scales. The nanoscale is in the range of $0 \cdot 1 \mu \mathrm{m}$ or $1000 \mathrm{~nm}$ to $0 \cdot 1 \mathrm{~nm}$. However, the novel and unique properties of materials are developed at the nanoscale range of 1-100 nm due to the small size (Hornyak et al., 2008). Therefore, nanotechnology is a study that is concerned with materials at a nanometre size of $1-100 \mathrm{~nm}$. The International Standards Organization states that a nanoparticle is a particle that has all three dimensions in the range of 1-100 nm (Shatkin, 2012). Nanomaterials are formed from nanoparticles. Nanostructured materials, on the other hand, comprise one-nano-dimensional (nano thin films), two-nano-dimensional (nanotubes and nanofibres) and three-nano-dimensional nanomaterials (nanopowders and nanoparticles) (Pokropivny et al., 2007). At the present time, nanomaterials such as nanoclay, nanosilica and nanocarbon are introduced frequently in the pavement engineering field.

The unique properties of nanomaterials can be attributed to their nano-size. The factor that makes the nanoscale unique compared with other scales is that it has a larger surface area than the same volume of material in a larger size (Calicut University, 2013; EHS, 2016; Pokropivny et al., 2007). A small particle size leads to a large surface area and the large surface area can cause exposure to more collisions and increase the frequency of collisions. Hence, the rate of reaction will increase and the material will become more chemically reactive. In pavement engineering, the interfacial forces between the nanomaterials and the asphalt binder will be enhanced, which will increase the strength and hardness of the materials. It is important to control their composition, size and structure (Calicut University, 2013). This is to ensure that the desired properties of nanomaterials can be achieved.

A few past studies that focused on the performance of asphalt binders modified by nanomaterials in terms of physical and rheological properties have been reviewed. Alhamali et al. (2015) added nanosilica in asphalt binder PG 76 and the results showed that the penetration and softening point values were decreased and increased, respectively. Meanwhile, the complex modulus $\left(G^{*}\right)$ was decreased except for the $6 \%$ nanosilica addition. The overall results indicated that $6 \%$ of nanosilica was the optimum content to improve bitumen in terms of rutting and fatigue cracking. Research done by Yao et al. (2013) showed that adding nanosilica in bitumen PG 58 leads to a decrease of viscosity. The complex modulus $\left(G^{*}\right)$ of the nanosilica modified binder was decreased excludes the PAV aging sample at temperature of $13^{\circ} \mathrm{C}$ in which the $G^{*}$ was increased. Meanwhile, Jamshidi et al. (2015), Yao et al. (2012) and You et al. (2011) reported that the incorporation of nanoclay in asphalt binder showed that non-modified nanoclay (NMN) had higher viscosity compared with polymer modified nanoclay (PMN) and control binders. With regard to dynamic shear rheometer (DSR) testing, Yao et al. (2012) found that the complex shear modulus $\left(G^{*}\right)$ of NMN and PMN were higher and lower than the control binder, respectively. However, from the perspective of dissipated work per load cycle, PMN can improve the resilience to high temperature for unaged, shortterm aged and long-term aged binders because they have an enhanced ability to recover compared with NMN binders.

In addition to the above-mentioned studies, the utilisation of nanocarbon powder and nanorubber powders in asphalt binders has been investigated by Yao et al. (2011). Different percentages of the nanomaterials were used in bitumen 60/80. The penetration and softening point tests were decreased and increased, respectively. Shafabakhsh and Ani (2015) used nano-titanium dioxide and nano-silicon dioxide in bitumen PEN 60/70 and the mixtures used natural aggregates with 50\% steel slag. Based on the binder properties test, the penetration and softening point values were decreased and increased, respectively. The viscosity also increased and the DSR showed that the modified bitumen had higher resistance to rutting. 

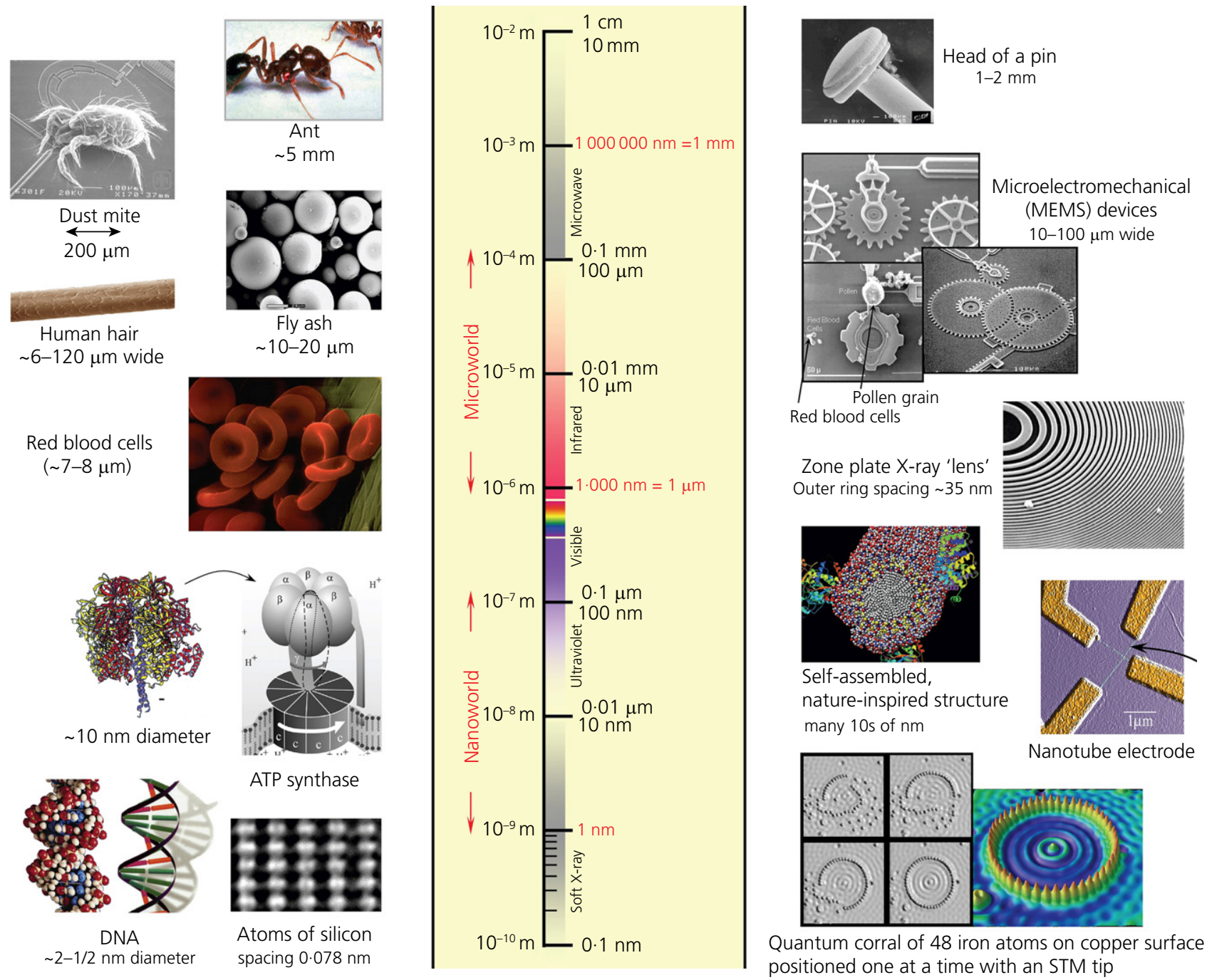

Red blood cells

Zone plate X-ray 'lens' Outer ring spacing $\sim 35 \mathrm{~nm}$

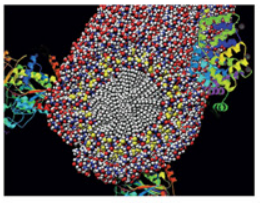

Self-assembled, nature-inspired structure many 10 s of $\mathrm{nm}$

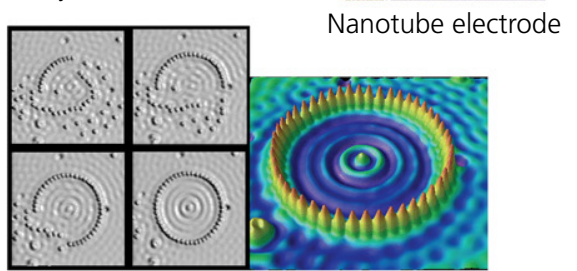

Quantum corral of 48 iron atoms on copper surface positioned one at a time with an STM tip

Figure 1. Scale of various objects (Nanohub, 2012)

Carbon nanofibres were utilised by Khattak et al. (2012) in three types of bitumen and binder properties tests were conducted. The results indicated that the carbon-nanofibremodified bitumen showed an improved viscoelastic response and resistance to rutting. Simultaneously, fatigue life was increased.

Based on past studies, nanomaterials are able to improve the properties of the conventional asphalt binder. It is therefore the aim of this study to investigate the production of nano charcoal from CS as a potential modifier in asphalt binders. The characteristics of nano charcoal ash (NCA) from CS waste are explored in terms of the microstructure of the charcoal and the physical properties of the NCA in the asphalt binder.

\section{Materials and methods}

\subsection{Materials}

The materials used in this study are described in the following subsections.

\subsubsection{Bitumen}

Bitumen PEN 60/70 from Shell, Malaysia was used. The physical properties are shown in Table 1.

\subsubsection{NCA CS}

\subsubsection{CHARCOAL PRODUCTION}

Figure 2 shows the processes used to produce NCA. First, the collected waste CS from Peter Haw Enterprise, Melaka, Malaysia was cleaned by removing the excessive coconut 
meat and fibrous husk. The CSs were then crushed using a crusher machine prior to the burning process, as shown in Figure 2(a). The CSs were burned in a furnace at a temperature of $450^{\circ} \mathrm{C}$ for $5 \mathrm{~min}$ to produce charcoal with high carbon content and to reduce the impurities in the raw CS. The sufficient amount of CS that can be burned in a furnace using a ceramic bowl was about $30-50 \mathrm{~g}$ (as shown in Figure 2(b)). Hence, after several trials, 5 min were enough to turn the CS into charcoal to prevent excessive burning of the CS as well.

\subsubsection{GRINDING PROCESS}

Subsequently, charcoal CS with a size of $75 \mu \mathrm{m}$ was fed into the ball mill and was subjected to five different grinding times, which were NCA1, 2, 3, 4 and 5. The charcoal was ground to form charcoal powder with a nanoparticle size (Figure 2(c)). The virgin binder as the control sample and the non-grinding charcoal ash sample designated as NCA0 were compared with the ground samples (NCA1 to 5) in the bitumen properties and rheological tests. Table 2 provides descriptions of each sample.

\subsection{Methods}

\subsubsection{Microstructure test}

Microstructure tests to analyse the thermal properties and morphology of the CS and charcoal CS were carried out.

(a) Thermogravimetric and derivative thermogravimetric analysis (TGA/DTA) (Figure 3(a)): Thermogravimetry

Table 1. Physical properties of bitumen $60 / 70$

$\begin{array}{lc}\text { Penetration at } 25^{\circ} \mathrm{C}: \mathrm{dmm} & 61 \cdot 7 \\ \text { Softening point: }{ }^{\circ} \mathrm{C} & 46.5 \\ \text { Rutting parameter, } \mathrm{G}^{\star} / \sin \delta \text { at } 64^{\circ} \mathrm{C}: \mathrm{kPa} & 1 \cdot 19\end{array}$

analyser model STA 8000 was used to perform

TGA/DTA analysis. The sample was heated at a heating rate of $20^{\circ} \mathrm{C} / \mathrm{min}$ from $28^{\circ} \mathrm{C}$ to $900^{\circ} \mathrm{C}$ under nitrogen gas protection.

(b) X-ray fluorescence (XRF): The chemical compositions of the CS and charcoal CS were examined using XRF. The materials were analysed in the form of powder $<75 \mu \mathrm{m}$.

This test was carried out at the Universiti Sains Malaysia, Penang, Malaysia.

(c) Field emission scanning electron microscopy (FESEM) (Figure 3(b)): The morphology analysis was performed by FESEM model Hitachi SU8020 with elemental analysis by energy dispersive X-rays. The sample was coated with gold prior to surface analysis.

(d) Particle size analysis (PSA): The average particle size of the ground charcoal (NCA1 to 5) was obtained using a particle size analyser by the technique of dynamic light scattering. This instrument can measure particle and molecule sizes ranging from $20 \mathrm{~nm}$ to $2000 \mu \mathrm{m}$.

\subsubsection{Bitumen physical properties test}

Bitumen physical properties tests on the nano charcoal CS-modified bitumen were conducted as follows.

(a) Mixing method: All the samples in Table 1 were used to replace $30 \%$ by weight of bitumen $60 / 70$. The mixing process was conducted using a high-shear mixer at speeds of $1500 \mathrm{r} / \mathrm{min}$ for $60 \mathrm{~min}$ at a temperature of $180^{\circ} \mathrm{C}$. These parameters were chosen based on past studies to ensure adequate mixing between NCA and bitumen to produce a homogeneous binder.

(b) Penetration test: The penetration test was used to check the consistency of the bitumen. This test was carried out according to ASTM D5 (ASTM, 2013). The bitumen was

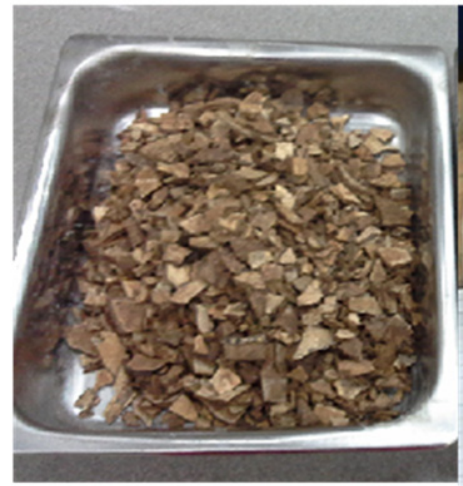

(a)

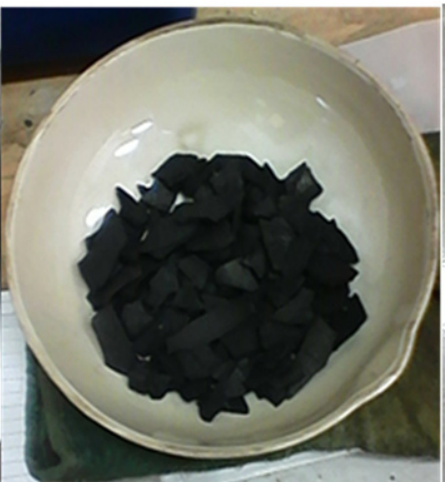

(b)

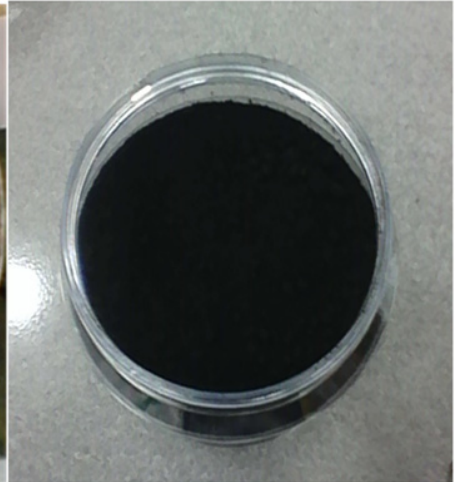

(c)

Figure 2. Processes to form NCA from CS: (a) CS, (b) charcoal CS, (c) nano charcoal CS 
heated and poured into a penetration cup prior to testing. The sample was then placed into a water bath for $1 \mathrm{~h}$ at $25^{\circ} \mathrm{C}$ after it was cooled. The penetration equipment was used to perform the test with an applied total load of $100 \mathrm{~g}$ for $5 \mathrm{~s}$ at a temperature of $25^{\circ} \mathrm{C}$.

(c) Softening point test: This test was performed in accordance with ASTM D36 (ASTM, 2000). The bitumen was heated and poured into two rings and cooled for $30 \mathrm{~min}$. The two rings and two ball centring guides were placed on the ring holder in a liquid bath. Subsequently, $3.5 \mathrm{~g}$ of steel balls were placed on each sample and heated. The temperature that made the bitumen touch the base plate was taken, and the mean temperature of the two samples was calculated.

(d) Dynamic shear rheometer (DSR) test: DSR was carried out according to ASTM D7175 (ASTM, 2015). The test was conducted at temperatures between 46 and $82^{\circ} \mathrm{C}$, with increments of $6^{\circ} \mathrm{C}$. For the unaged bitumen, a $1 \mathrm{~mm}$ thick plate and $25 \mathrm{~mm}$ diameter top plate were used. The bitumen sample was sandwiched between two $1 \mathrm{~mm}$ thick plates. Stress was applied on top of the sample by the $25 \mathrm{~mm}$ diameter top plate, which oscillated at $1.59 \mathrm{~Hz}$, to

Table 2. Samples used in this study

\begin{tabular}{lc} 
Designation & Grinding: $\mathbf{h}$ \\
\hline Virgin binder & - \\
NCA0 & 0 \\
NCA1 & 20 \\
NCA2 & 30 \\
NCA3 & 40 \\
NCA4 & 50 \\
NCA5 & 60 \\
\hline
\end{tabular}

measure the maximum stress, maximum strain and time lag of stress and strain. The rutting performance of the asphalt pavements was analysed from $G^{*} / \sin \delta$.

\section{Results and discussion}

\subsection{Microstructural analysis}

\subsubsection{TGA/DTA}

A TGA/DTA test was carried out to examine the thermal properties of the charcoal. The relationship between TGA and DTA is shown in Figure 4, showing how the CS was formed into the charcoal CS. Three endothermic peaks are shown in the graph, namely, endothermic peaks 1, 2 and 3. As shown in Table 3, endothermic peak 1 occurs at $68.7^{\circ} \mathrm{C}$ (range $50-110^{\circ} \mathrm{C}$ ) with a weight loss of $2 \cdot 8 \%$, indicating the loss of moisture from volatile compounds through evaporation (Vargas-Delgadillo et al., 2010).

Another weight loss peak of $4.8 \%$ was observed in the temperature range $110-410^{\circ} \mathrm{C}$, at endothermic peak 2 at $195^{\circ} \mathrm{C}$. This increase was due to the decomposition of the CS components and the initiation of carbonisation through the evaporation of volatile compounds (Vargas-Delgadillo et al., 2010). Hence, the temperature range from 50 to $410^{\circ} \mathrm{C}$ indicated the devolatilisation process of CS (Ouyang et al., 2013; VargasDelgadillo et al., 2010). The endothermic peak 3 at $490^{\circ} \mathrm{C}$ (range $410-690^{\circ} \mathrm{C}$ ) presented a weight loss of $18.6 \%$ due to the decomposition of cellulose, lignin and pentosans, and carbon formation (Ouyang et al., 2013; Vargas-Delgadillo et al., 2010).

At this stage, charcoal CS without volatile compounds was obtained. The decomposition of the components continued at

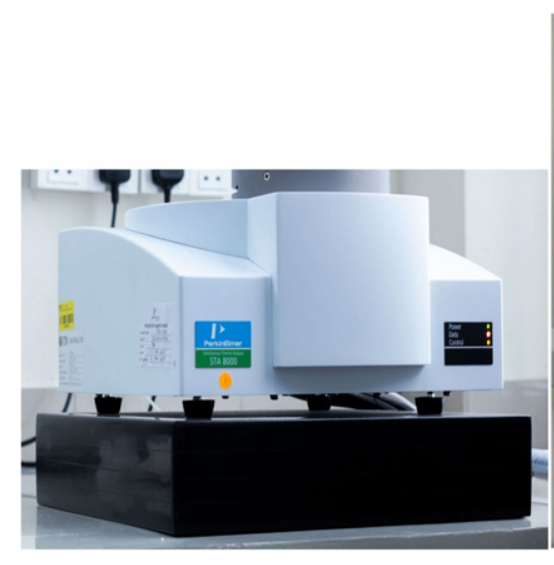

(a)

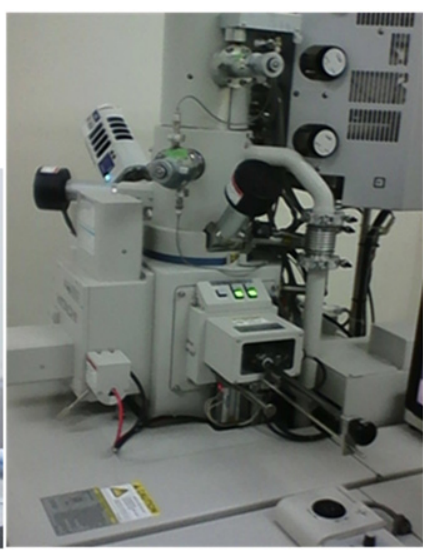

(b)

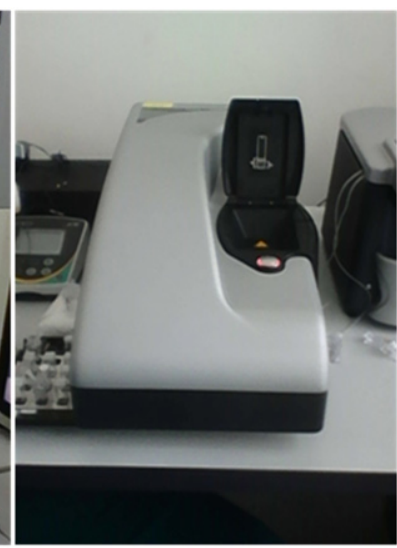

(c)

Figure 3. Instruments used for microstructure test: (a) thermogravimetry analyser; (b) FESEM; (c) PSA 


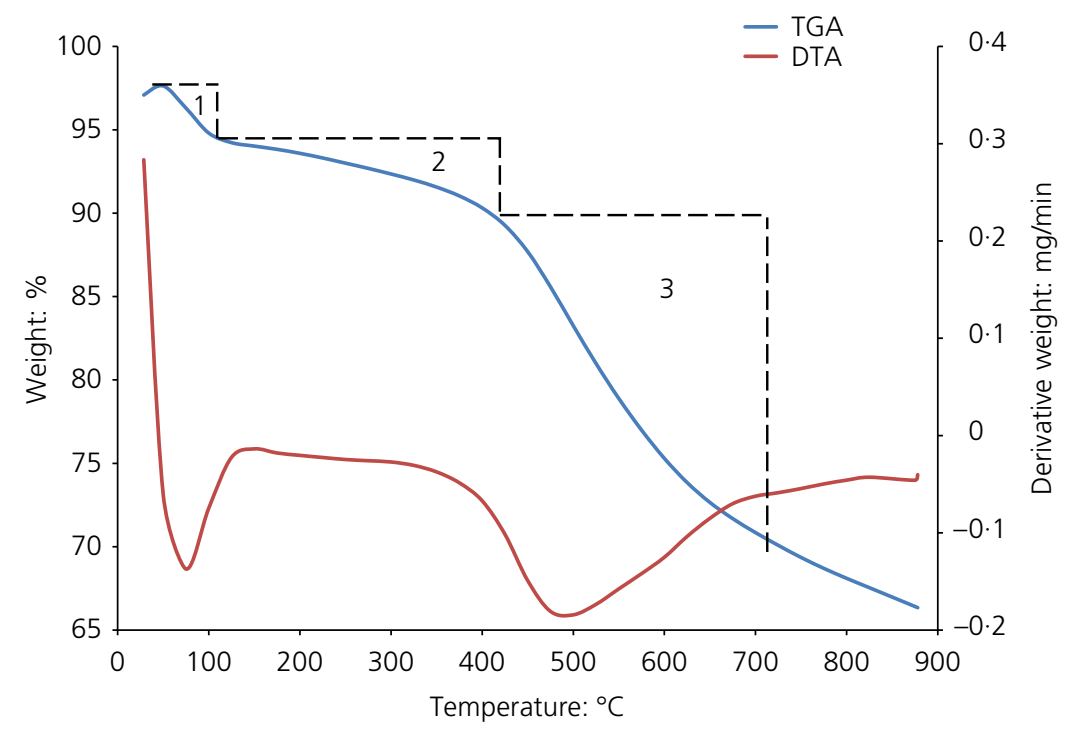

Figure 4. TGA/DTA curves of charcoal CS

Table 3. Weight loss of charcoal CS

\begin{tabular}{|lrcc|}
$\begin{array}{l}\text { Endothermic } \\
\text { peak }\end{array}$ & $\begin{array}{c}\text { Temperature } \\
\text { range: }{ }^{\circ} \mathrm{C}\end{array}$ & $\begin{array}{c}\text { Weight } \\
\text { loss: \% }\end{array}$ & $\begin{array}{c}\text { Maximum } \\
\text { peak: }{ }^{\circ} \mathrm{C}\end{array}$ \\
\hline 1 & $50-110$ & $2 \cdot 8$ & $68 \cdot 7$ \\
2 & $110-410$ & $4 \cdot 8$ & 195 \\
3 & $410-690$ & $18 \cdot 6$ & 490 \\
\hline
\end{tabular}

a low rate until a temperature of $900^{\circ} \mathrm{C}$ was achieved (Ouyang et al., 2013). Based on this analysis, the most suitable temperature for burning $\mathrm{CS}$ was $490^{\circ} \mathrm{C}$. This value was supported by the research conducted by Ouyang et al. (2013) and Zhao et al. (2014a, 2014b) where they stated that the optimum pyrolysis temperature was between 400 and $500^{\circ} \mathrm{C}$.

\subsubsection{Chemical properties}

The chemical compositions of the CS before and after the heat treatment were examined to discover the chemical properties of the materials. This test is important to examine the types of chemical elements that exist in CS and charcoal CS, and also to reduce impurities. According to Read and Whiteoak (2003), the major chemical element in bitumen is carbon at $82-88 \%$ based on the chemical analysis from various bitumens. Therefore, material with a high content of carbon was expected to be compatible with asphalt binder. Zhao et al. (2014a, 2014b) state that various studies have been conducted using carbon-based materials to modify asphalt binder because of the compatibility of both materials.

Table 4 presents the chemical compositions of both CS and charcoal CS. It can be seen that the carbon content of CS
Table 4. Chemical properties

$\begin{array}{lcc}\text { Chemical compositions: \% } & \text { Coconut shell } & \text { Charcoal CS } \\ \text { Carbon }(\mathrm{C}) & 96.20 & 99.70 \\ \text { Sodium oxide }\left(\mathrm{Na}_{2} \mathrm{O}\right) & 0.0688 & 0.0079 \\ \text { Magnesium oxide }(\mathrm{MgO}) & 0.0991 & 0.0161 \\ \text { Silicon dioxide }\left(\mathrm{SiO}_{2}\right) & 0.7997 & 0.0486 \\ \text { Diphosphorus pentoxide }\left(\mathrm{P}_{2} \mathrm{O}_{5}\right) & 0.2579 & 0.0250 \\ \text { Sulfur trioxide }\left(\mathrm{SO}_{3}\right) & 0.2158 & 0.0125 \\ \text { Chlorine }(\mathrm{Cl}) & 0.3513 & 0.0137 \\ \text { Potassium oxide }\left(\mathrm{K}_{2} \mathrm{O}\right) & 1.3451 & 0.0740 \\ \text { Iron (III) oxide }\left(\mathrm{Fe}_{2} \mathrm{O}_{3}\right) & 0.1696 & 0.0731 \\ \text { Nickel(II) oxide }(\mathrm{NiO}) & 0.0050 & 0.0012\end{array}$

and charcoal CS is $96 \cdot 2$ and $99 \cdot 7 \%$, respectively. Both contain a high proportion of carbon. The carbon formation, as explained in Section 3.1.1, led to the increase in percentage of carbon from $96 \cdot 2$ to $99 \cdot 7 \%$. Meanwhile, the impurities in CS such as silica, iron, potassium, sodium and other elements that exist in the materials were decreased after the burning process. However, it should be noted that the chemical composition according to the Centre for Chemical and Structural Analysis (CCSA) also depended on the CS source - that is, the way the charcoal was prepared and the presence of contaminants.

\subsubsection{FESEM}

Figure 5 shows the morphology of the CS prior to burning. As shown in Figure 5(a), CS presents packed discrete structures with a length of $15.4 \mathrm{~mm}$ and width of $100 \mu \mathrm{m}$. In between these structures, pores with sizes of $578 \mathrm{~nm}$ to $1.4 \mu \mathrm{m}$ exist, as shown in Figure 5(b), with an image size of $20 \mu \mathrm{m}$. The CS 


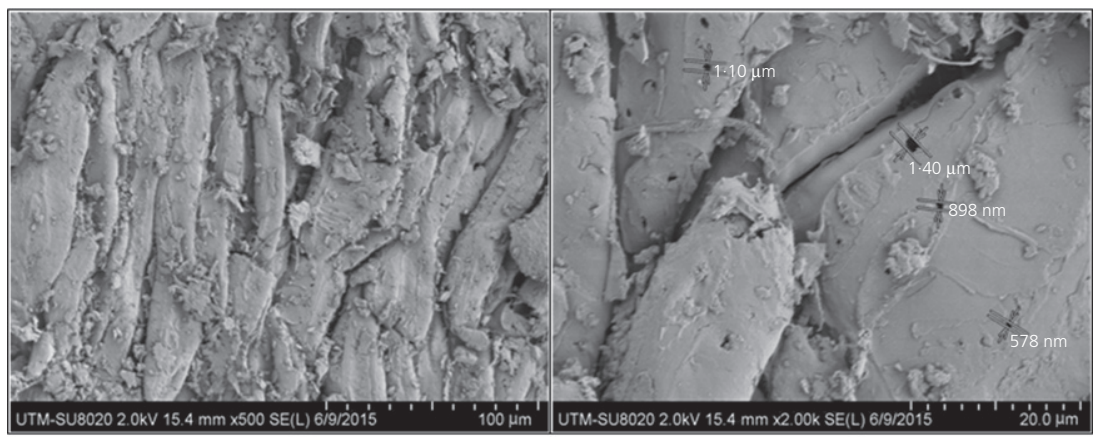

(a)

(b)

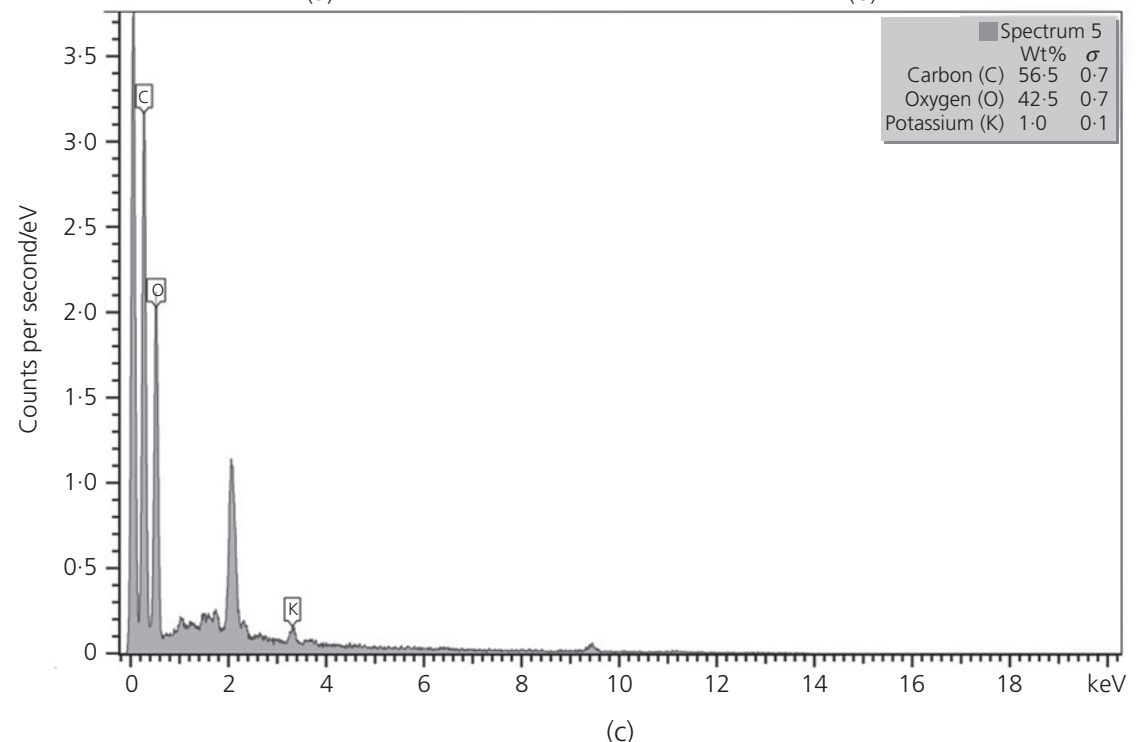

Figure 5. FESEM images and EDX of CS. (a) CS image at 500 magnification factor; (b) CS image at 2K magnification factor; (c) EDX of CS

surface was rough, with elongated layers and irregularly shaped. The elements detected by energy-dispersive X-ray spectroscopy (EDX) on the surface of the sample were $56.5 \%$ carbon, $42.5 \%$ oxygen and $1 \%$ potassium, as shown in Figure 5(c).

The charcoal CS in Figure 6(a) shows discrete structures but fine surfaces with a length of $16.8 \mathrm{~mm}$. The morphology of the product was of smooth, porous, sharp-edged and flat-shaped particles. The pore sizes ranged from $915 \mathrm{~nm}$ to $1.54 \mu \mathrm{m}$, as shown in Figure 6(b). The EDX in Figure 6(c) shows a carbon content of $77 \cdot 6 \%$, oxygen content of $20 \cdot 2 \%$ and $2 \cdot 2 \%$ potassium. This increase in carbon content could be attributed to the high burning temperature employed, which removed surface functional groups and formed a porous surface over the charcoal CS (Ouyang et al., 2013). A porous surface leads to a larger surface area, which generates more interlocking bonding between particles. The rate of absorption and interaction bonding will increase immediately.
The percentages of elements discovered by the EDX were limited only to the surface of the materials. This is the reason why the materials' compositions obtained by X-ray fluorescence (XRF) in Table 2 were different from the EDX results. Furthermore, the compositions were also influenced by the size of the CS and charcoal CS material used for FESEM analysis, which was solid instead of powder, which was the required state for XRF analysis. However, the carbon content was still the highest detected in the materials.

\subsubsection{PSA}

Based on Figure 7, the particle sizes of the ground samples were $>100 \mathrm{~nm}$ but $<1000 \mathrm{~nm}$. The optimum size was obtained by NCA2, which was $148 \mathrm{~nm}$, where the charcoal had been ground for $30 \mathrm{~h}$. In addition, it can be seen that, as the grinding time was increased, the particle size was increased too. This might be due to the agglomeration that occurred when the optimum time for grinding was exceeded. 
Construction Materials

Volume 172 Issue CM2
Microstructure and physical properties of

nano charcoal ash as binder

Jeffry, Putra Jaya, Abdul Hassan, Mirza

and Mohd Yusak

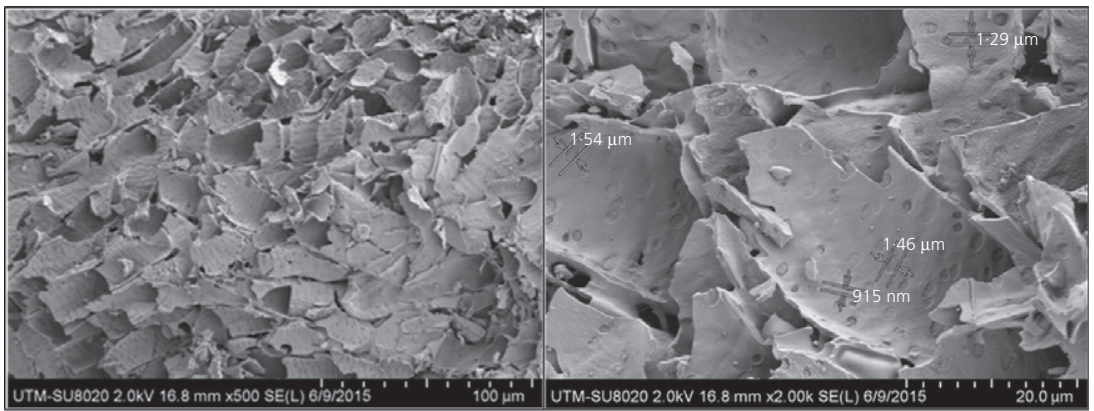

(a)

(b)

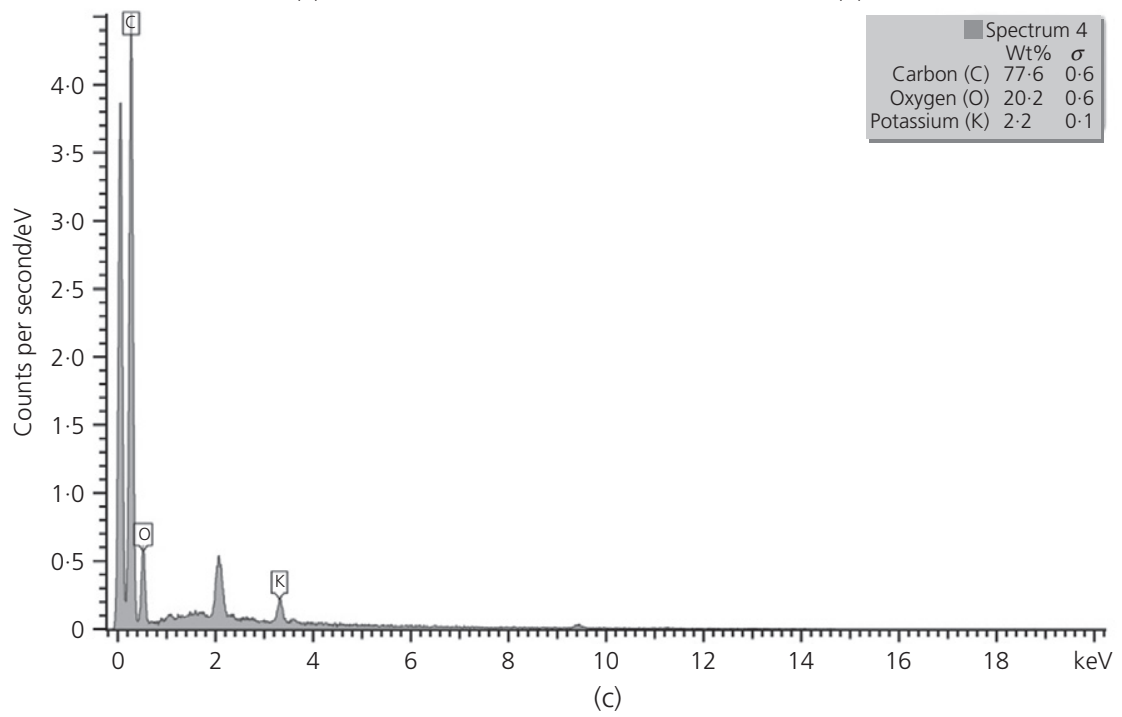

Figure 6. FESEM images and EDX of charcoal CS. (a) Charcoal CS image at 500 magnification factor; (b) Charcoal CS image at $2 \mathrm{k}$ magnification factor; (c) EDX of charcoal CS

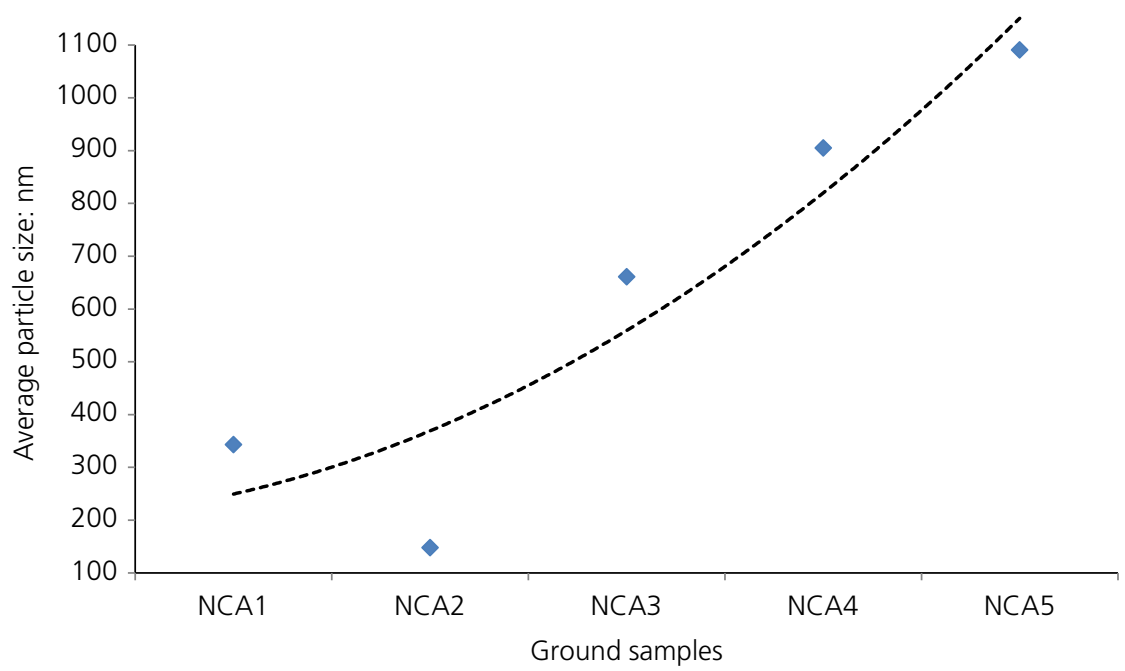

Figure 7. Particle size of ground samples 


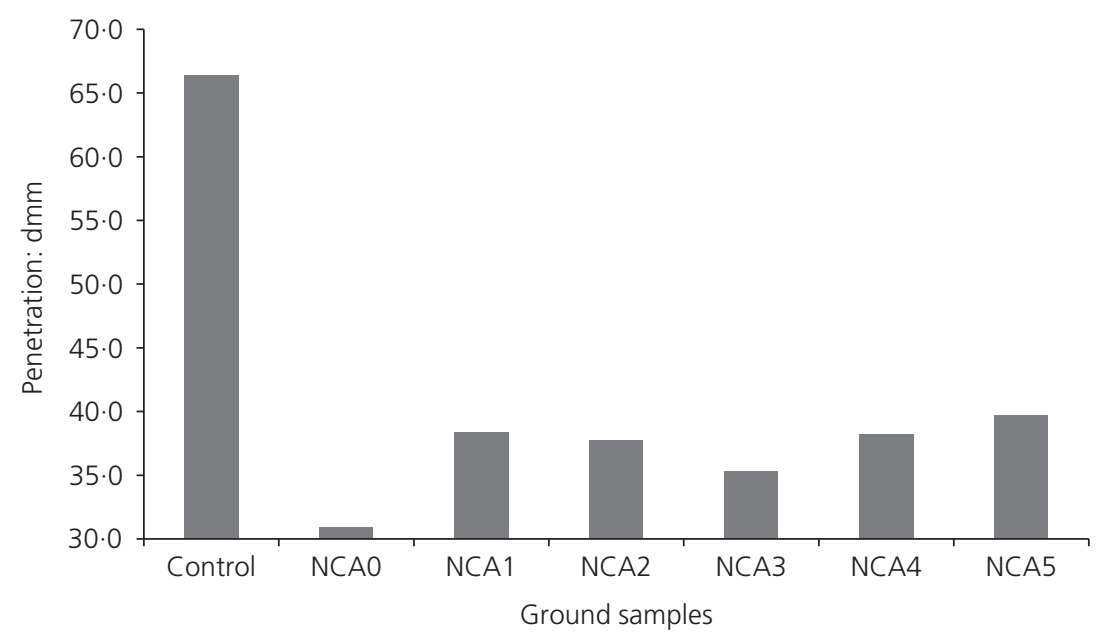

Figure 8. Penetration values of bitumen modified by NCA

As mentioned earlier, the novel properties of materials were developed at a nanoscale of $1-100 \mathrm{~nm}$. The particle sizes obtained in this study, however, did not achieve a particle size $<100 \mathrm{~nm}$, yet remained in the nanometre range as almost all of the samples had a size $<1 \mu \mathrm{m}$. Throughout this analysis, the method of grinding needs to be modified in terms of many factors, including the grinding times to obtain the desired size of the nanomaterials.

In addition, the effects of these samples on the asphalt binder are investigated in Section 3.2.

\subsection{Bitumen property and rheological test}

In this section, the virgin binder as the control sample and the unground charcoal ash sample designated as NCA0 are compared with NCA1, 2, 3, 4 and 5.

\subsubsection{Penetration test}

Figure 8 shows the penetration values of the modified bitumen samples that were compared with the virgin binder as a control sample. Based on the graph, the incorporation of NCAs into the bitumen gave lower penetration values than the virgin binder. The NCA0 showed the lowest penetration value compared with NCA1 to NCA5, which was $30.90 \mathrm{dmm}$. In this test, the NCA3 showed the lowest penetration value after the NCA 0 , which was $35 \cdot 30 \mathrm{dmm}$. The NCA3 was $14 \%$ softer and $47 \%$ stiffer than the NCA0 and the virgin binder, respectively. Therefore, $30 \%$ replacement by NCA can increase the stiffness of bitumen by half as much again. The internal strength of the bitumen improved as well. Although the NCA0 showed the greatest improvement, becoming too stiff is not good because it will cause a different problem in asphalt pavements. A low penetration value typically leads to high stiffness of the bitumen. However, if the bitumen is too stiff it will become less elastic and thereby the flexibility of the asphalt pavements is reduced. This can lead to cracking because the asphalt pavement cannot accommodate traffic loading (Astana, 2010). Hubbard and Gollomb (1973) reported that, when penetration occurred between 20 and $30 \mathrm{dmm}$, cracking could occur. When the penetration was $>30 \mathrm{dmm}$, the bitumen had a high resistance to cracking, when combined with proper mix design and compaction (Brown et al., 2009).

\subsubsection{Softening point test}

Based on the results shown in Figure 9, it can be seen that the NCA modified bitumen samples have higher softening point values compared with the virgin binder. The NCA3 had the highest softening point value, which was $50 \cdot 3^{\circ} \mathrm{C}$ and was $12 \%$ higher than the virgin binder. Meanwhile, the lowest softening point value was acquired by $\mathrm{NCA} 5$, which was $48 \cdot 3^{\circ} \mathrm{C}$ and was $7 \%$ higher than the virgin binder. A high softening point indicated that the binder was less susceptible to temperature. Even though the penetration value of NCA0 was better than that of NCA3, in the softening point test, the value was lower than those of the NCA3 and NCA4 by $\sim 2$ and $0 \cdot 4 \%$, respectively. This showed that the phase change of NCA3 modified bitumen to fluid was lowered where the temperature at which the bitumen softens was high. The physical properties of the control sample and modified samples were determined through their consistency. Based on the penetration test, the consistency of the bitumen at the same temperature was determined at a temperature of $25^{\circ} \mathrm{C}$, while the temperature at which the bitumen reached the consistency was determined by the softening point value. The penetration index (PI) was therefore calculated to determine the compatibility of the bitumen. 


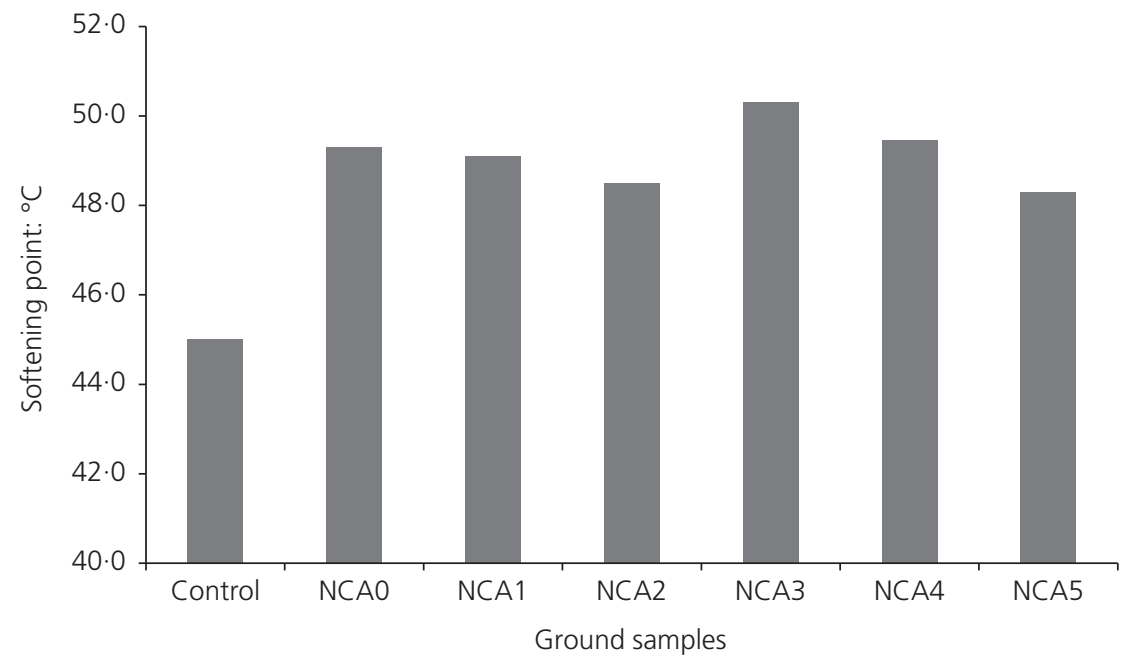

Figure 9. Softening point of bitumen modified by NCA

\subsubsection{P}

The PI is used to determine the temperature susceptibility of bitumen, in which the consistency of the softening point is expressed in terms of penetration, by a linear extrapolation of the logarithm of penetration against temperature (Read and Whiteoak, 2003). The PI value can be obtained either by a nomograph or an equation as (Read and Whiteoak, 2003)

1. $\mathrm{PI}=\frac{1951 \cdot 4-500 \log P-20 \mathrm{SP}}{50 \log P-\mathrm{SP}-120 \cdot 14}$

where $P$ is Penetration and SP is softening point.

Read and Whiteoak (2003) reported that the range of PI is between -3 for highly temperature susceptibility of bitumen and +7 for highly blown low-temperature susceptibility (high PI) of bitumen. However, the suitable PI for road construction was between -1 and +1 (Brown et al., 2009). A low value of PI, which approaches a negative value, means that the sample has high susceptibility at low temperature, which can lead to cracking. On the other hand, a high value of PI, which approaches a positive value, indicates low susceptibility at high temperature, which leads to high resistance to permanent deformation or rutting. Based on the results in Table 5, the PI for the virgin binder and NCA modified bitumen did not lie within the range from -1 to +1 . However, NCA1 to NCA4 still lay in between -2 and +2 if following the PI range stated by Domone and Illston (2010) for road use. The lowest PI was obtained by NCA0, which was $-2 \cdot 3$. According to Brown et al. (2009) the bitumens that had PI lower than -2 were typically susceptible to low temperatures, thereby leading to brittleness and transverse cracking during cold weather. By contrast,
Table 5. PI value

$\begin{array}{lc}\text { Ground sample } & \text { Penetration index } \\ \text { Control } & -1 \cdot 9 \\ \text { NCA0 } & -2 \cdot 3 \\ \text { NCA1 } & -2 \cdot 0 \\ \text { NCA2 } & -2 \cdot 0 \\ \text { NCA3 } & -1 \cdot 8 \\ \text { NCA4 } & -1.9 \\ \text { NCA5 } & -2 \cdot 1\end{array}$

the highest PI was gained by the virgin binder, NCA3 and NCA4 with values of $-1.9,-1.8$ and -1.9 , respectively. The less negative value showed that the sample had been improved (Hadavand, 2010). The NCA0 approached a more negative value, which meant that the sample was highly influenced by temperature compared with samples NCA1 to NCA5.

\subsubsection{Dynamic shear rheometre}

The rutting performance of the modified asphalt binders was compared with that of the virgin binder as shown in Figure 10. It can be seen that the modified samples have higher rutting resistance compared with the control sample. In this test, the rutting parameter $G^{*} / \sin \delta$ was the parameter used to indicate the resistance to deformation of the binder at pavement service temperatures. The control sample resisted the rutting up to the temperature of $64^{\circ} \mathrm{C}$ with $G^{*} / \sin \delta$ of $1.19 \mathrm{kPa}$ and then failed at a temperature of $70^{\circ} \mathrm{C}$. The sample that could withstand rutting at the highest temperature was NCA2. It resisted rutting at a temperature of $76^{\circ} \mathrm{C}$ with a rutting parameter of $1.03 \mathrm{kPa}$, prior to failure at a temperature of $82^{\circ} \mathrm{C}$. The other modified samples all failed at the temperature of $76^{\circ} \mathrm{C}$, which 


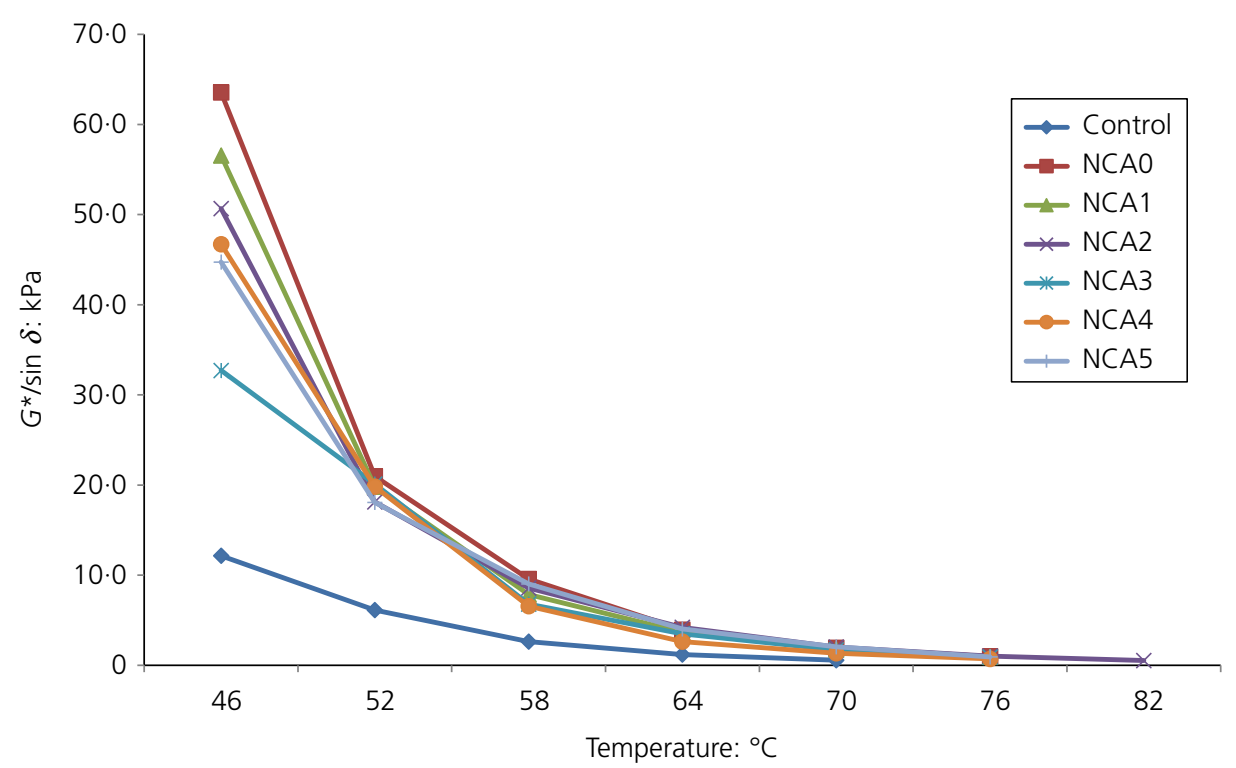

Figure 10. Rutting parameter of the modified samples

was higher than for the control sample. This test showed that the modified samples have improved a lot, especially the NCA2-modified bitumen. The reason NCA2 had a higher rutting parameter than the other samples was because of the particle size of the NCA. The particle size of NCA2 was $148 \mathrm{~nm}$, which was the smallest size compared with the other NCAs. Through the DSR, the effects of the particle size in the modification of the bitumen was more obvious than through the consistency tests. It showed that the nanosized particles at almost $<100 \mathrm{~nm}$ had improved the properties of the virgin binder more than other samples with a particle size $<1000 \mathrm{~nm}$. This can be attributed to the large surface area of the particles, which increased the bonding between the particles. The rate of reaction also increased at the same time, and enhanced the rheological properties of the bitumen.

\section{Conclusion}

The use of waste materials in the nanosize range from 1 to $100 \mathrm{~nm}$ has not been investigated in the asphalt binder. The novelty of this research stems from the nanosize itself, which can improve the properties and performance of asphalt binder in a unique way. Based on this study, the XRF test detected the carbon element in NCA, which was $99 \cdot 7 \%$ after the burning process in which carbon was formed at a temperature of $490^{\circ} \mathrm{C}$ based on the result of TGA/DTA test. Also, the FESEM results showed that charcoal CS presents smoother, more porous and more irregularly shaped particles than CS. In terms of the particle size, the optimum size was obtained by NCA2 with a size of $148 \mathrm{~nm}$. The charcoal CS was ground for $30 \mathrm{~h}$. Meanwhile, the results obtained by the penetration and softening point tests showed that the modified samples were improved. The PI for NCA1 to NCA4 was still in the range of -2 to +2 , which indicated that the samples have high resistance to temperature changes. Nevertheless, the DSR test showed that NCA2 has higher resistance to deformation compared with other modified samples due to its nanosized particles, which approached $100 \mathrm{~nm}$.

It can be seen that different grinding times have affected the particle size of the material. The performance of the modified bitumen has also been influenced by the different sizes of the particles. The method of grinding therefore needs to be adjusted to obtain a particle size of charcoal in the nanoscale of $1-100 \mathrm{~nm}$. At this scale the novel properties of the materials can be obtained. Subsequently, the nano charcoal will be incorporated in asphalt binder and asphalt mixtures. Thorough analysis will be carried out on the performance of the nano charcoal in the asphalt mixture. In addition, the effects of short-term ageing of this material during mixing and compaction of the mixture on site need to be investigated. A detailed analysis of the costing of the nano charcoal to be used in asphalt pavements will be implemented as well. Finally, this study has shown that NCA has great potential to be utilised in asphalt binders.

\section{Acknowledgements}

The support provided by the Malaysian Ministry of Higher Education and Universiti Teknologi Malaysia in the form of a research grant vote number Q.J130000·2522·11H58 for this study is greatly appreciated. 


\section{REFERENCES}

Agunsoye JO, Isaac TS and Samuel SO (2012) Study of mechanical behaviour of coconut shell reinforced polymer matrix composite. Journal of Minerals and Materials Characterization 2012(11): 774-779.

Agunsoye JO, Talabi SI, Bello SA and Awe IO (2014) The effects of Cocos nucifera (coconut shell) on the mechanical and tribological properties of recycled waste aluminium can composites. Tribology in Industry 36(2): 155-162.

Alhamali DI, Wu J, Liu Q et al. (2015) Physical and rheological characteristics of polymer modified bitumen with nanosilica particles. Arabian Journal for Science and Engineering, 41(4): 1521-1530.

Astana DA (2010) The Effect of Epoxy Bitumen Modification on Hot Mix Asphalt Properties and Rut Resistance. Universiti Teknologi Malaysia, Johor Bahru, Malaysia.

ASTM (2000) D36: Standard test method for softening point of bitumen (ring-and-ball apparatus). ASTM International, West Conshohocken, PA, USA.

ASTM (2013) D5: Standard test method for penetration of bituminous materials. ASTM International, West Conshohocken, PA, USA.

ASTM (2015) D7175: Standard test method for determining the rheological properties of asphalt binder using a dynamic shear rheometer. ASTM International, West Conshohocken, PA, USA.

Brown ER, Kandhal PS, Roberts FL et al. (2009) Hot Mix Asphalt Materials, Mixture Design and Construction, 3rd edn. NAPA Research and Education Foundation, Lanham, MD, USA.

Calicut University (2013) Nanoscience. Calicut University, Kerala, India. See http://cuiet.info/notes/chemistry/Nanoscience.pdf (accessed 21/03/2015)

Che Mat N, Putra Jaya R, Abdul Hassan N et al. (2014) Properties of asphaltic concrete containing Sasobit ${ }^{\circledR}$. Jurnal Teknologi 71(3): $27-31$

Domone P and Illston J (2010) Construction Materials: Their Nature and Behaviour, 4th edn. CRC Press, Boca Raton, FL, USA.

EHS (Environmental Health and Safety) (2016) Nanomaterials Handling Safety Guide for Laboratories. Environmental Health and Safety, Iowa City, IA, USA. See http://ehs.research.uiowa. edu/nanomaterials-handling-safety-guide-laboratories (accessed 21/02/2016)

FAOStat (Food and Agriculture Organization of the United Nations) (2015) Statistics Division. Food and Agriculture Organization of the United Nations, Rome, Italy. See http://faostat3.fao. org/browse/Q/*/E (accessed 15/11/2015).

Gunasekaran K (2011) Utilization of Coconut Shell as Coarse Aggregate in the Development of Lightweight Concrete. SRM University, Chennai, India. See http://shodhganga.inflibnet. ac.in//handle/10603/34574 (accessed 09/09/2015).

Gunasekaran K, Kumar PS and Lakshmipathy M (2011) Mechanical and bond properties of coconut shell concrete. Construction and Building Materials 25(1): 92-98.

Gunasekaran K, Annadurai R and Kumar PS (2012) Long term study on compressive and bond strength of coconut shell aggregate concrete. Construction and Building Materials 28(1): 208-215.

Gunasekaran K, Annadurai R and Kumar PS (2013) A study on some durability properties of coconut shell aggregate concrete. Materials and Structures 48(5): 1253-1264.

Hadavand BS (2010) Bitumen modification with polysulphide polymer prepared from heavy end waste. Iranian Polymer Journal (English Edition) 19(5): 363-373.
Hainin MR, Abdulridha AA, Yaacob H, Haron Z and Md Yusoff NI (2013) Fatigue life of Malaysia hot mix asphalt mixtures. Malaysia Journal of Civil Engineering 25(1): 94-105.

Hainin MR, Putra Jaya R, Ali Akbar NA, Jayanti DS and Md Yusoff NI (2014) Influence of palm oil fuel ash as a modifier on bitumen to improve aging resistance. Journal of Engineering Research 2(1): 34-46.

Hainin MR, A Aziz, MM, Adnan AM et al. (2015) Performance of modified asphalt binder with tire rubber powder. Jurnal Teknologi 73(4): 55-60.

Hornyak GL, Dutta J, Tibbals HF and Rao A (2008) Introduction to Nanoscience. CRC Press, Boca Raton, FL, USA.

Hubbard P and Gollomb H (1973) The hardening of asphalt with relation to development of cracks in asphalt pavements. Transportation Research Board, Washington, DC, USA. Proceedings AAPT, 9, pp. 165-194.

Husseinsyah S and Zakaria MM (2011) The effect of filler content on properties of coconut shell filled polyester composites. Polymer 6(1): 87-97.

Jamshidi A, Mohd Hasan MR, Yao H, You Z and Hamzah MO (2015) Characterization of the rate of change of rheological properties of nano-modified asphalt. Construction and Building Materials 98: $437-446$

Jeffry SNA, Putra Jaya R, Manap N, Miron NA and Abdul Hassan N (2016) The influence of coconut shell as coarse aggregate in asphalt mixture. Key Engineering Materials 700: 227-237.

Khattak MJ, Khattab A, Rizvi HR and Zhang P (2012) The impact of carbon nano-fiber modification on asphalt binder rheology. Construction and Building Materials 30(5): 257-264.

Kumar S and Kumar B (2012) Study of mechanical properties of coconut shell particle and coir fibre reinforced epoxy composite. International Journal of Advances in Engineering Research 4(2): 39-62.

Madakson PB, Yawas DS and Apasi A (2012) Characterization of coconut shell ash for potential utilization in metal matrix composites for automotive applications. International Journal of Engineering Science and Technology 4(3): 1190-1198.

Nanohub (2012). The Scale of Things - Nanometers and More. Nanohub, West Lafayette, IN, USA. See https://nanohub.org/ resources/13842 (accessed 15/11/2016).

Nath Giri A (2015) What is Activated Charcoal?. EHSQ (Environment, Health, Safety and Quality), Mumbai, India. See http://quality605. rssing.com/chan-12050655/all_p89.html (accessed 27/04/2016).

Norhafizah M, Ramadhansyah PJ, Siti Nur Amiera J et al. (2016) The effect of coconut shell on engineering properties of porous asphalt mixture. Jurnal Teknologi 78(7-2): 127-132.

Ouyang S, Xu S, Song N and Jiao S (2013) Coconut shell-based carbon adsorbents for ventilation air methane enrichment. Fuel 113(11): $420-425$

Pokropivny V, Hussainova I, Lohmus R, Porkropivny A and Vlassoy S (2007) Introduction to Nanomaterials and Nanotechnology. University of Tartu, Tartu, Estonia.

Pukird S, Chamninok P, Samran S et al. (2009) Synthesis and characterization of $\mathrm{SiO}_{2}$ nanowires nanowires prepared from rice husk ash. Journal of Metals, Materials and Minerals 19(2): 33-37.

Ramadhansyah PJ, Nurfatin Aqeela M, Siti Nur Amiera J et al. (2016) Use of coconut shell from agriculture waste as fine aggregate in asphaltic concrete. ARPN Journal of Engineering and Applied Sciences 11(12): 7457-7462.

Rampe MJ, Setiaji B and Trisunaryanti W (2011) Fabrication and characterization of carbon composite from coconut shell carbon. Indonesian Journal of Chemistry 11(2): 124-130. 
Read J and Whiteoak D (2003) The Shell Bitumen Handbook, 5th edn. Thomas Telford Publishing, London, UK. See http://books.google. com/books?id=bA1tIkRJL8kC\&pgis=1 (accessed 13/02/2016).

Sapuan SM, Harimi M and Maleque MA (2003) Mechanical properties of epoxy/coconut shell filler particle composites. The Arabian Journal for Science and Engineering 28(2): 171-181.

Sarki J, Hassan SB, Aigbodion VS and Oghenevweta JE (2011) Potential of using coconut shell particle fillers in eco-composite materials. Journal of Alloys and Compounds 509(5): 2381-2385.

Shafabakhsh GH and Ani OJ (2015) Experimental investigation of effect of nano $\mathrm{TiO}_{2} / \mathrm{SiO}_{2}$ modified bitumen on the rutting and fatigue performance of asphalt mixtures containing steel slag aggregates. Construction and Building Materials 98(11): 692-702.

Shatkin JA (2012) Nanotechnology: Health and Environmental Risks, 2nd edn. CRC Press, Boca Raton, FL, USA.

Singh A (2013) Study of mechanical properties and absorption behaviour of coconut shell powder-epoxy composites. International Journal of Materials Science and Applications 2(5): 157 .

Sivapragasam A (2008) Coconut in Malaysia - current developments and potential for re-vitalization. Proceedings of 2 nd International Plantation Industry Conference and Exhibition (IPICEX2008), Selangor, Malaysia. MARDI, Shah Alam, Malaysia, pp. 1-9.
Vargas-Delgadillo DP, Giraldo L and Moreno-Piraján JC (2010) Preparation and characterization of activated carbon monoliths with potential application as phenol adsorbents. E-Journal of Chemistry 7(2): 531-539.

Yao H, Li L, Xie H, Dan HC and Yang XL (2011) Microstructure and performance analysis of nanomaterials modified asphalt. In Road Materials and New Innovations in Pavement Engineering (Walubita LF, Hajj EY, Dafalla M and Liu Z (eds)). American Society of Civil Engineers, Reston, VA, USA, Geotechnical Special Publication 223, pp. 220-228.

Yao H, You Z, Li L et al. (2012) Performance of asphalt binder blended with non-modified and polymer-modified nanoclay. Construction and Building Materials 35(10): 159-170.

Yao H, You Z, Li L et al. (2013) Rheological properties and chemical bonding of asphalt modified with nanosilica. Journal of Materials in Civil Engineering 25(11): 1619-1630.

You Z, Mills-Beale J, Foley JM et al. (2011) Nanoclay-modified asphalt materials: preparation and characterization. Construction and Building Materials 25(2): 1072-1078.

Zhao S, Huang B, Shu X and Ye P (2014a) Laboratory investigation of biochar-modified asphalt mixture. Transportation Research Record: Journal of the Transportation Research Board, 2445: 56-63.

Zhao S, Huang B, Ye XP, Shu X and Jia X (2014b) Utilizing bio-char as a bio-modifier for asphalt cement: a sustainable application of bio-fuel by-product. Fuel 133(10): 52-62.

\section{How can you contribute?}

To discuss this paper, please email up to 500 words to the editor at journals@ice.org.uk. Your contribution will be forwarded to the author(s) for a reply and, if considered appropriate by the editorial board, it will be published as discussion in a future issue of the journal.

Proceedings journals rely entirely on contributions from the civil engineering profession (and allied disciplines).

Information about how to submit your paper online is available at www.icevirtuallibrary.com/page/authors, where you will also find detailed author guidelines. 